\title{
Enhanced Screening for Ectasia Risk prior to Laser Vision Correction
}

\author{
${ }^{1}$ Renato Ambrósio Jr, ${ }^{2}$ Michael W Belin
}

\section{ABSTRACT}

Aim: To prospectively review current understanding and future trends of screening for keratectasia risk prior refractive laser vision correction (LVC).

Background: Progressive keratectasia is an uncommon but severe complication of LVC. Preoperative ectatic corneal disease is the most important risk factor. Screening for subclinical ectasia relies on proper interpretation of advanced diagnostic technologies, including front surface corneal topography, three-dimensional tomography, and biomechanical assessments.

Summary: Studies involving eyes with normal and stable corneas, compared to eyes with frank ectatic diseases and to eyes with normal topography from patients with very asymmetric ectasia, allow for developing advanced methods and testing its sensitivity. However, the ideal study populations for testing the sensitivity and specificity of ectasia risk assessments are respectively the preoperative of cases that developed ectasia and the ones with stable outcomes after LVC. Young age and low thickness are surrogates of corneal biomechanics, which may be replaced as risk factors by direct measurements. Keratectasia may also occur due to the surgical impact on corneal structure or due to significant trauma postoperatively. Percentage tissue altered higher than $40 \%$ is a more sensitive parameter than a fixed value for minimal residual stromal bed of $250 \mu \mathrm{m}$. However, the biomechanical impact from surgery is related to the region and number of lamellae that are severed, so that flap thickness and geometry should play a more relevant role, which is in agreement with finite element simulations. Artificial intelligence methods allow for combining parameters, which significantly enhance the accuracy for detecting ectasia risk.

Conclusion: An enhanced screening approach for preventing keratectasia should consider both preoperative patient-related data and procedure-related parameters to individually characterize ectasia susceptibility or predisposition.

Clinical Significance: Keratectasia is an uncommon, however, severe complication of LVC. Although prevention is the best

\footnotetext{
${ }^{1}$ Founder and Research Director, ${ }^{2}$ Professor

${ }^{1}$ Rio de Janeiro Corneal, Tomography and Biomechanics Study Group (Rio de Janeiro, Brazil); Associate Professor, Department of Ophthalmology, Federal University of São Paulo (São Paulo Brazil); Director of Cornea and Refractive Surgery, Instituto de Olhos Renato Ambrosio (Rio de Janeiro, Brazil)

${ }^{2}$ Department of Ophthalmology and Vision Science, The University of Arizona, Tucson, Arizona, USA

Corresponding Author: Renato Ambrósio Jr, Rua Conde de Bonfim 211/712 20520-050, Rio de Janeiro RJ Brazil, Phone: 552122344233, e-mail: dr.renatoambrosio@gmail.com
}

strategy, an individualized enhanced ectasia screening approach for ectasia risk assessment prior to LVC procedures should integrate patient-related (individual ectasia susceptibility) and procedure-related parameters (biomechanical impact).

Keywords: Ectasia susceptibility, Keratectasia, Keratoconus, Laser vision correction.

How to cite this article: Ambrósio Jr R, Belin MW. Enhanced Screening for Ectasia Risk prior to Laser Vision Correction. Int J Kerat Ect Cor Dis 2017;6(1):23-33.

\section{Source of support: Nil}

Conflict of interest: None

\section{INTRODUCTION}

"There are known knowns. These are things we know that we know. There are known unknowns. That is to say, there are things that we know we do not know. But there are also unknown unknowns. There are things we do not know we do not know."

- Donald Rumsfeld

Progressive "iatrogenic" keratectasia after laser in situ keratomileusis (LASIK), defined as progressive corneal steepening with secondary loss of visual acuity, was first reported in 1998 by Seiler. ${ }^{1}$ While the actual incidence of ectasia is undetermined, the incidence rate falls between relatively high levels of $0.66^{2}$ and $0.57 \%,{ }^{3}$ down to $0.2 \%$, $0.05 \%,{ }^{5} 0.04 \%$, ${ }^{6}$ or $0.029 \%$ (Schallhorn, unpublished data 2013). Nonetheless, ectasia was recognized as a very severe complication of laser vision correction (LVC) procedures. ${ }^{7,8}$ This was because of the very high potential for vision impairment or morbidity, causing frustration for refractive surgeons and dissatisfaction among patients. There is also a high risk for litigation, malpractice liability claims, and lawsuits related to progressive ectasia after LVC. Major attempts for understanding and preventing keratectasia have been taken. ${ }^{8,9}$

Ectasia occurs due to a biomechanical failure of the corneal stroma, leading to thinning and protrusion, which is associated with interlamellar and interfibrillar slippage with interfiber fracture, as seen in histopathologic and ultrastructural studies. ${ }^{9}$ This occurs due to the inability of the corneal tissue to support the unremitting stresses caused by intraocular pressure, extraocular muscles actions, eyelid blinking, and other forces, such as eye rubbing. ${ }^{10,11}$ Since the first report, ${ }^{1}$ the hypothesis that post-LASIK ectasia occurred due to the structural impact from the procedure on a cornea with altered biomechanical properties was considered. Risk factors 
Table 1: Risk factors for keratectasia

\begin{tabular}{l}
\hline 1 Preoperative susceptibility of the cornea (weak \\
biomechanical properties): \\
- Preoperative ectatic corneal disease \\
- Young age \\
- Low preoperative pachymetry \\
2 Severe biomechanical impact from surgery: \\
- High percentage of altered tissue (PTA $\geq 40 \%)$ \\
- Low residual stromal bed (RSB) due to excessive laser \\
ablation for high corrections or multiple retreatments (RSB \\
$\leq 250$ mm or $1 / 2$ of pre-op thickness) \\
- Thick LASIK flap \\
- Small treatment zone, causing abnormal focal stress \\
distribution \\
3 Severe trauma after surgery: \\
- Aggressive eye rubbing \\
- Other sources of blunt corneal trauma
\end{tabular}

for ectasia may be related to three factors (Table 1): (1) Preoperative structural abnormalities, such as keratoconus (clinical or subclinical), ${ }^{7,12}$ or high susceptibility of the cornea due to weak innate biomechanical properties, ${ }^{8}$ (2) severe biomechanical impact from surgery, ${ }_{1}^{12,13}$ and (3) severe trauma after surgery, such as vigorous eye rubbing in response to allergic conjunctivitis, to cause (possibly unilaterally) post-LASIK keratectasia without other known predisposing risk factors. ${ }^{11}$

Long-term stability after LVC will be determined by the combination of the preoperative biomechanical strength of the patient's corneal stroma, the amount of biomechanical alteration caused by the surgery, and the postoperative stress load to the cornea. Understanding current diagnostic technology for characterizing the cornea preoperatively and the implications of keratorefractive procedures on the corneal structure are the main pillars for assessing ectasia risk prior to refractive surgery.

\section{WHAT ARE WE SCREENING FOR? DEFINING ECTASIA SUSCEPTIBILITY}

"If you know the enemy and know yourself, you need not fear the result of a hundred battles. If you know yourself but not the enemy, for every victory gained you will also suffer a defeat. If you know neither the enemy nor yourself, you will succumb in every battle." - Sun Tzu, The Art of War

Identifying cases at high risk or susceptibility for biomechanical failure after LVC represents a major challenge for refractive surgeons. The screening is defined as the application of a diagnostic test to detect cases with mild to moderate disease or with high susceptibility or predisposition for developing disease. ${ }^{8}$ It is typically applied to prevent suffering and morbidity, when treatment decisions can best alter the natural course for the patient.

Placido disk-based corneal topography is sensitive to detect abnormal front curvature patterns of ectatic disease in 1 patients with relatively normal distance corrected visual acuity and unremarkable biomicroscopy. ${ }^{7,8,14}$ Corneal topography and central corneal thickness (CCT) have a recognized, but limited role for screening refractive candidates. ${ }^{14}$ In an attempt to improve screening efficiency, the ectasia risk scoring system (ERSS) was developed by Randleman and coworkers. The ERSS found abnormal topography as the most important risk factor for ectasia development, ${ }^{12}$ considering also the impact from surgery and other patient's preoperative data. Level of refractive correction, residual stromal bed (RSB), and patient's age were clinical variables other than corneal topography and CCT that were integrated in this score system. The combined approach represented an improvement, however, there were still $8 \%$ false negatives and $6 \%$ false positives found at the original ERSS study. ${ }^{12}$ Also, a much higher incidence of both false positive ${ }^{15}$ and false negatives ${ }^{16}$ have been reported. This was, at least in part, related to the criteria for classifying corneal topography. In fact, Ramos et al reported significant interobserver variability in subjective classifications of corneal topography maps. ${ }^{17}$ Changing from an absolute to a normative scale increased the scores on the classifications by the same examiner, with significant intraobserver variability. ${ }^{17}$ Objective quantitative indices, such as the classic Rabinowitz inferior-superior dioptric asymmetry value (I-S) and the keratoconus percentage index (KISA), and qualitative pattern of asymmetric bow tie with skewed radial axes was an attempt to add objective measurement to the previous subjective evaluation. ${ }^{7}$

It is fundamental to consider that normal topography does not exclude mild or early ectatic corneal disease. ${ }^{8,18-22}$ For example, there are subclinical cases with normal topography, such as those from patients with keratoconus in the fellow eye (Figs 1 to 5). Whereas these cases have been considered to demonstrate enhanced accuracy of corneal tomography, ${ }^{18,20-25}$ they do not represent the ideal study population for assessing high susceptibility or predisposition for ectasia progression. This is because some of these patients may have unilateral mechanically induced ectatic disease, ${ }^{20,21,23}$ due to unilateral stimuli, such as chronic eye rubbing. ${ }^{11}$ Interestingly, this is a consensus that true unilateral keratoconus does not exist, ${ }^{26}$ and that ectasia may occur due to mechanical causes. ${ }^{26}$ Whereas only longitudinal follow-up studies are able to elucidate such cases, ${ }^{7}$ these cases have been referred as forme fruste keratoconus (FFKC) in the unaffected eye with normal topography ${ }^{18,20,25}$ However, FFKC may not be an accurate term, as it was originally described by Marc Amsler (18911961) based on reflection Placido-disk photography, prior to the development of computerized corneal imaging technologies. The FFKC was used to describe an abortive form of the disease that may progress or not. ${ }^{7,20,27}$ 


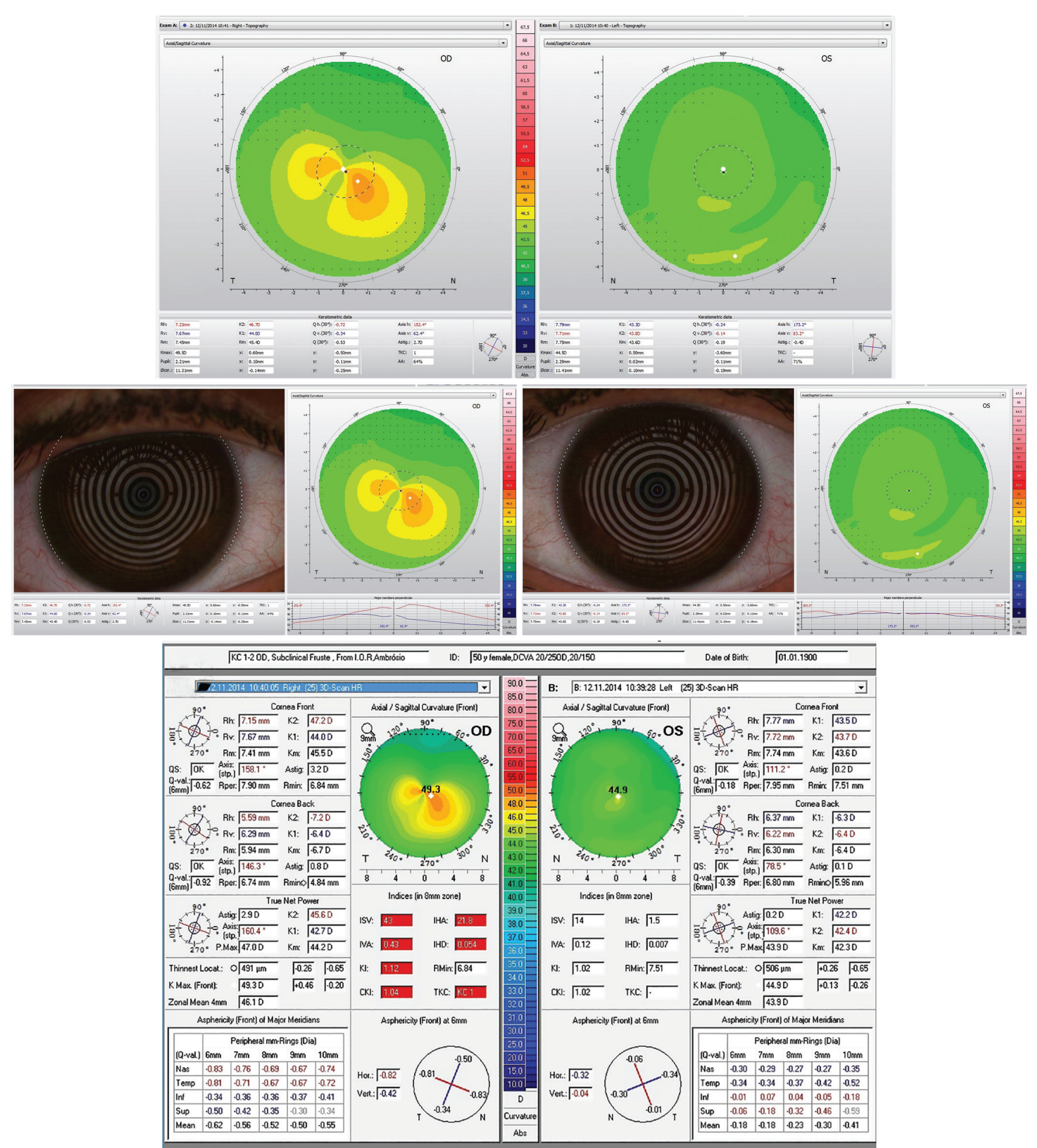

Fig. 1: Placido-disk based (Oculus Keratograph 5 TM; A, B and C) and Scheimpflug (Oculus Pentacam HR; D) curvature maps with Smolek-Klyce absolute 1.5D scale, from a female patient with 50 years old. She presents with very asymmetric keratoconus. OD has mild keratoconus while OS has a normal curvature map (forme fruste). Note the similarity of the generated maps from these different technologies. Uncorrected distance visual acuity was 20/200 in both eyes; MRx was $-0.75=-2.25 \times 81^{\circ}$, giving 20/25 in OD and -2.00 $=0.50 \times 115^{\circ}$, giving $20 / 15$ in OS

The need for enhancing the sensitivity for detecting mild or subclinical ectatic disease is also supported by the reported cases of ectasia after LASIK without identifiable risk factors (clinical example 2 - Figs 6 and 7). ${ }^{28,29}$ These cases, when a thick flap or excessive tissue ablation are excluded, represent the closest to the ideal popula- tion for the studies involving screening for ectasia risk. In fact, the analysis of the preoperative data from these cases has provided the most important advances in the field. ${ }^{8} 12$ 29,30 Many of the reported cases, however, had limited preoperative data to front surface curvature and $\mathrm{CCT}$, which restricts their study potential. ${ }^{8}$ 
OCULUS - PENTACAM Belin / Ambrósio Enhanced Ectasia

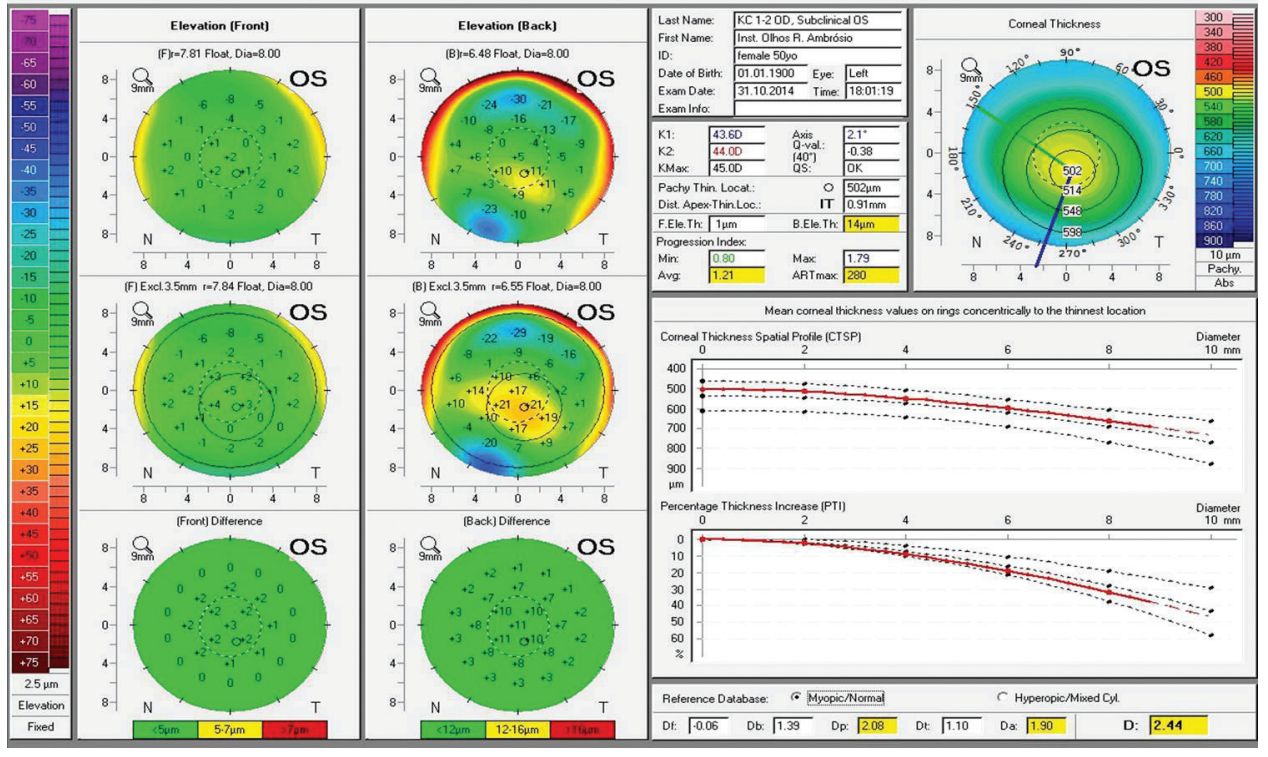

Fig. 2: Belin/Ambrósio enhanced ectasia display (BAD) from the left eye (same case as Figs 1 to 5)
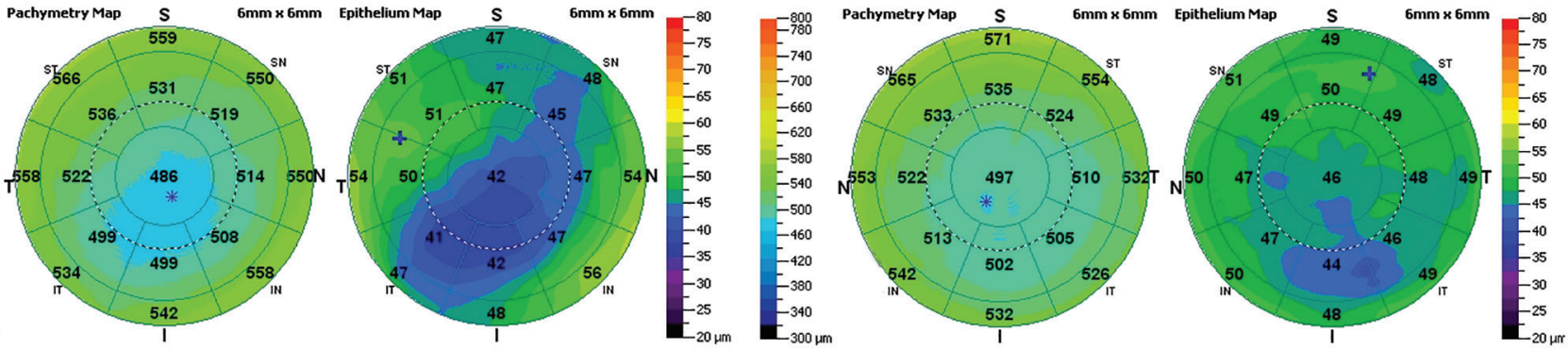

Fig. 3: Segmental Tomography with OCT-FD (RtVue; Optovue, Freemont, CA) from the right: (A) left eye; and (B) of the same case as Figures 1 to 5
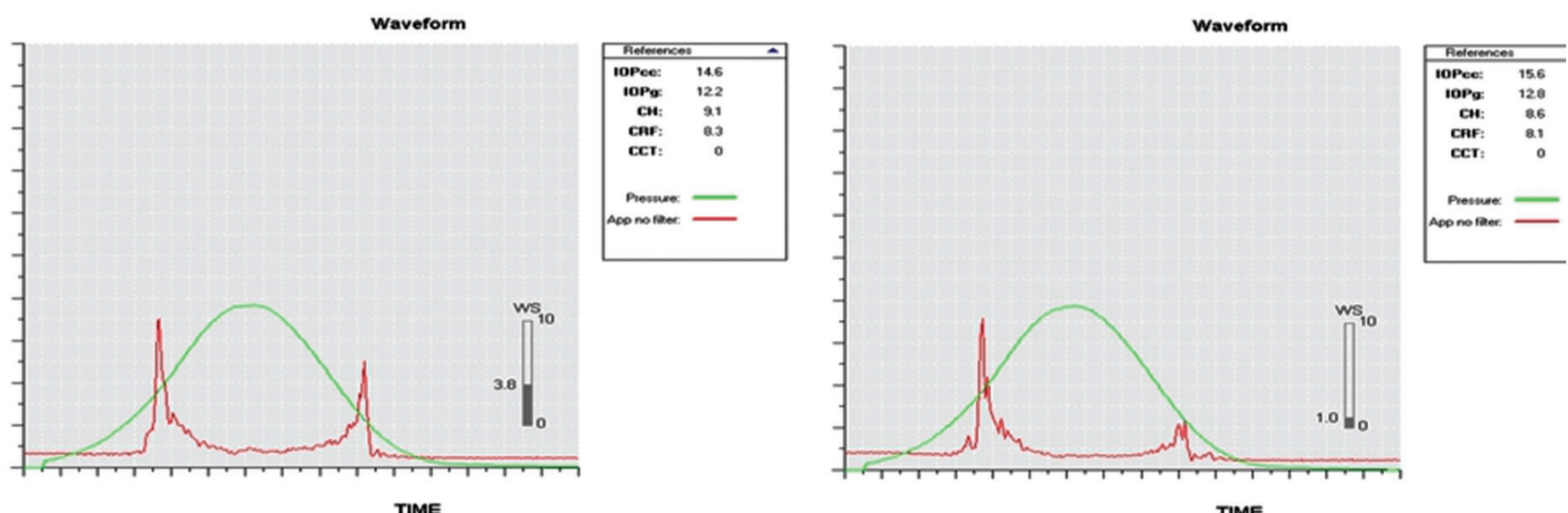

Fig. 4: Ocular response analyzer of the right (A) and left (B) eyes (same case as Figures 1 to 5 )

Another major concept is that any cornea can undergo ectasia progression, if there is enough disturbances from surgery and/or by other environmental factors, such as ocular trauma and eye rubbing. ${ }^{8,11}$ This is in agreement with the current consensus, ${ }^{26}$ and with the two-hit hypothesis. ${ }^{31}$ The goal, therefore, is not solely to detect or screen for mild or subclinical keratoconus, but to assess individual's susceptibility for ectasia progression, ${ }^{22}$ and also depends on the biomechanical impact from the LVC procedure. ${ }^{8,18}$ 


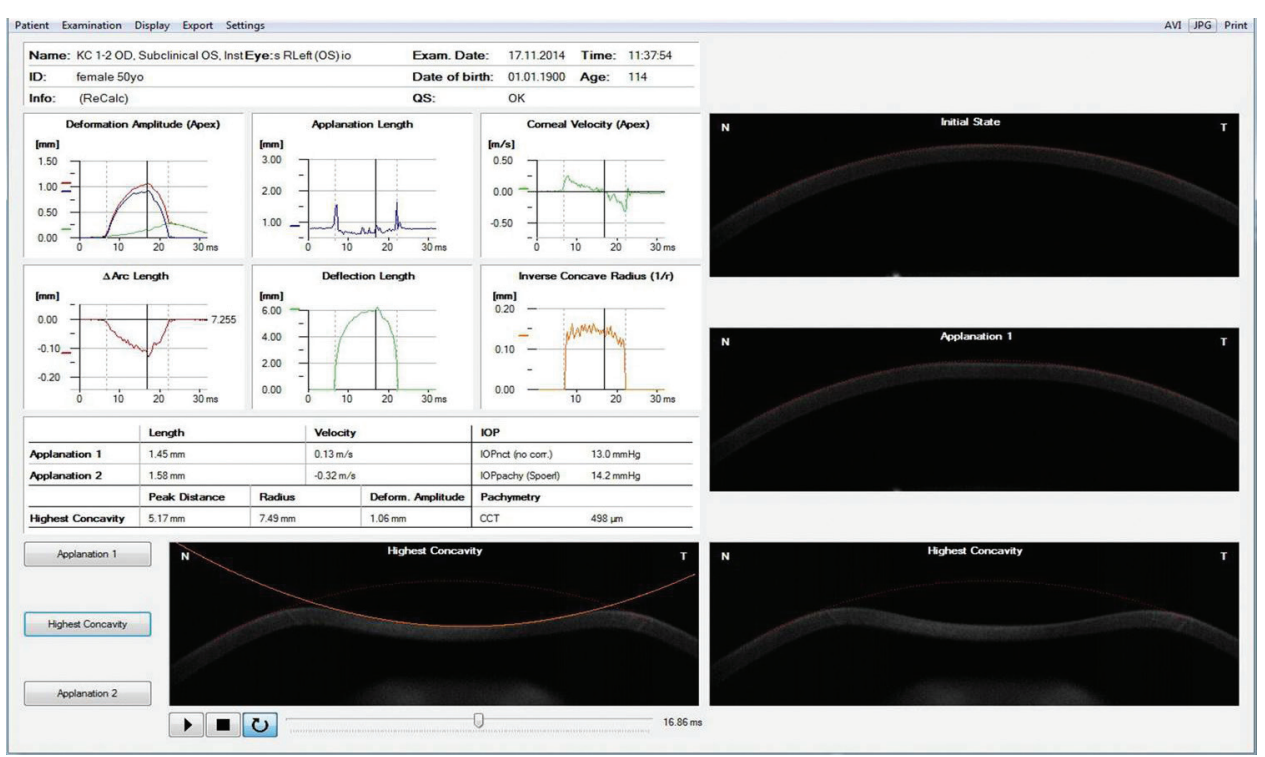

Fig. 5: Corvis ST of the left eye (same case as Figs 1 to 5); CBI was 0.61

OCULUS - PENTACAM Compare 2 Exams

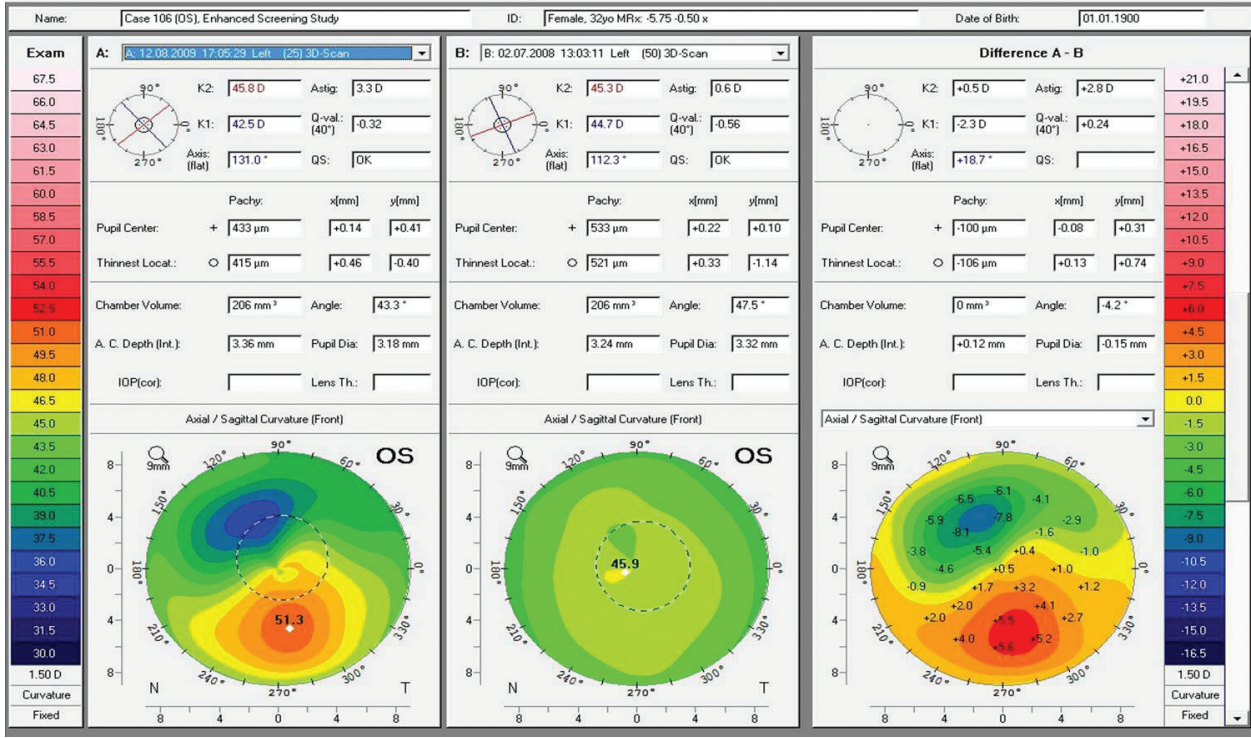

Fig. 6: Curvature maps from the Postoperative and from the Pre-LASIK from a female patient with 32 years old, MRx: $-5.75-0.50 \times 95^{\circ}(20 / 20)$

\section{Advanced Corneal Analysis beyond Curvature}

"Corneal tomography" provides a three-dimensional reconstruction of the corneal shape, enabling the calculations of elevation maps of the front and back surfaces of the cornea, along with pachymetric mapping. ${ }^{18,20}$ In addition, the ability for epithelial thickness mapping by "segmental or "layered" tomography using optical coherence tomography $(\mathrm{OCT})^{32}$ and very high frequency ultrasound, ${ }^{33}$ may provide additional information for ectasia risk detection. For example, Reinstein and coworkers demonstrated improved specificity by verifying stability after LASIK in corneas with preoperative topographic abnormalities, but confirmed as non-ectasia susceptible by epithelial thickness profile in a retrospective case-control comparative study. ${ }^{33}$ Also, Sinha Roy's group developed the Bowman's roughness index (BRI), ${ }^{34}$ which characterizes the irregularity of the Bowman's layer. The BRI, in conjunction with epithelial thickness data and BAD-D, did improve the sensitivity for detecting mild forms of ectasia in studies involving the fellow eye with normal topography from very asymmetric ectasia (VAE) cases.

Corneal morphologic changes due to ectasia (including curvature, elevation, and thickness) are secondary signs of a primary structural ${ }^{9}$ or biomechanical ${ }^{10}$ abnormality. Roberts and Dupps have proposed that there is a focal biomechanical failure in ectasia, rather than a generalized weakening. ${ }^{35}$ The ocular response analyzer (ORA; Reichert, Buffalo, NY; Fig. 4), ${ }^{10,22,28}$ the Corvis ST 
OCULUS - PENTACAM Belin / Ambrósio Enhanced Ectasia

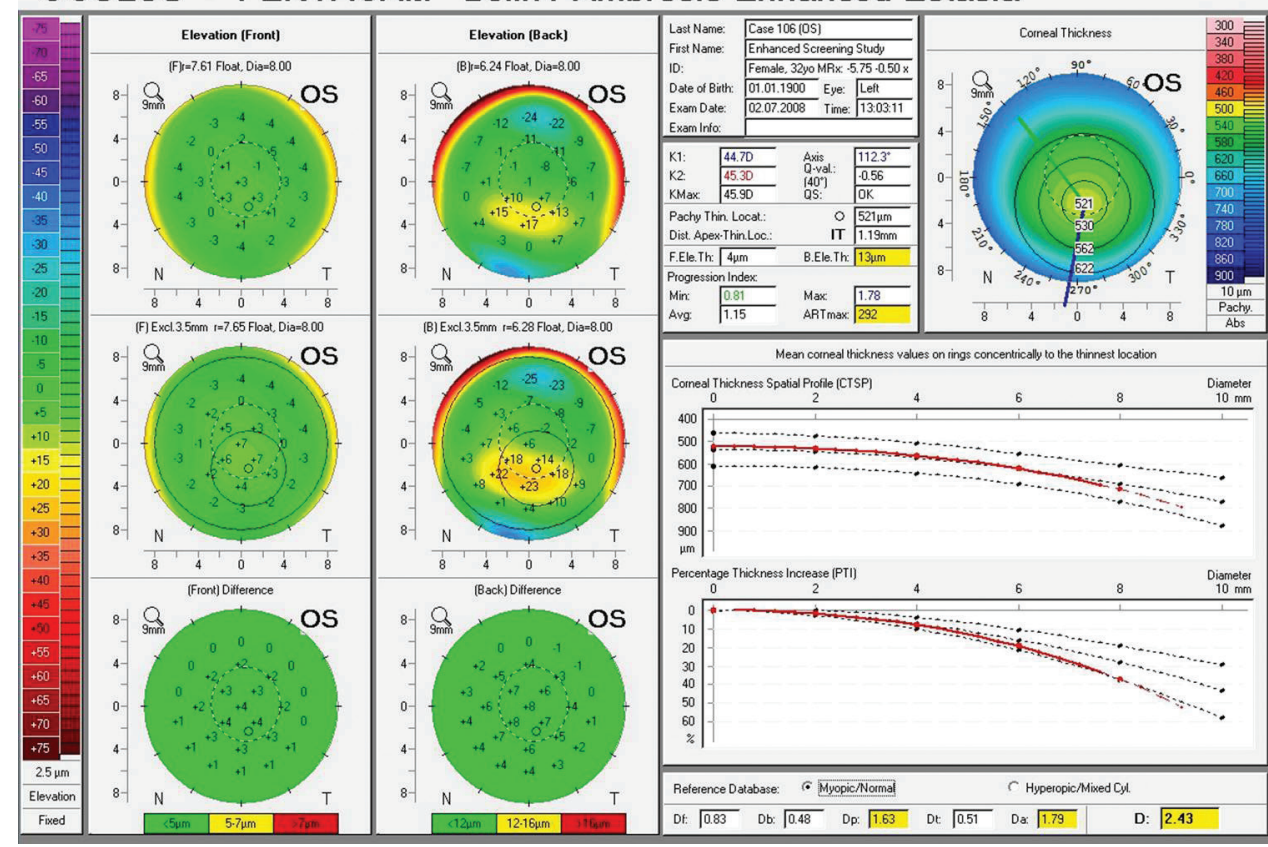

Fig. 7: Belin/Ambrósio enhanced ectasia display from the left eye (same case as Fig. 6)

(Oculus, Wetzlar, Germany; Fig. 5), 20,22 and Brillouin optical microscopy (Harvard Medical School, Boston, $\mathrm{MA})^{36}$ are promising technologies for the clinical assessment of the biomechanical properties of corneal tissue. Interestingly, the CBI (corneal biomechanical index) is a novel biomechanical index that was developed by Vinciguerra et al to integrate corneal deformation response metrics from the Corvis ST, having high accuracy to detect clinical ectasia. ${ }^{37}$ Ultimately, the integration of biomechanical data and corneal shape data has been proposed for further improving accuracy to detect mild ectasia or even its susceptibility. ${ }^{28,38}$

\section{BASICS AND PITFALLS FOR THE INTERPRETATION OF CLINICAL DATA}

The presentation of corneal elevation data in maps dependent on the reference surface choosen. ${ }^{39}$ In fact, the method of depicting the elevation is the subtraction of the measured surface (either front or back) and a reference shape, which is calculated to have the highest coincident points to a determined area of the cornea that was analyzed. The best-fit sphere (BFS) to the $8 \mathrm{~mm}$ zone has been recommended, as it provides adequate data points without the need to use extrapolated data for the majority of cases. ${ }^{19,20}$ The map pattern, the elevation values at the thinnest point (TP) and at maximum elevation within central 4-5 mm zone are the most important characteristics for clinical interpretation. ${ }^{19,20}$ Different reference shapes, such as the best-fit toric and aspheric ellipsoid may be used. ${ }^{25}$ Using the Pentacam, the cut-off criteria for the posterior elevation value at the TP using the BFS was $12 \mu \mathrm{m}$ and using the BFTE was $8 \mu \mathrm{m}$, with respectively sensitivity of 96.28 and $95.04 \%$ and specificity of 98.79 and $99.09 \%$ for detecting keratoconus. ${ }^{20}$ Using the Galilei analyzer (Ziemer Ophthalmic Systems AG, Port, Switzerland), the cut-off values for maximum posterior elevation within the central $5 \mathrm{~mm}$ diameter obtained by BFTA were 16 and $13 \mu \mathrm{m}$ for keratoconus and mild FFKC respectively, with sensitivities of 99 and $82 \%{ }^{25}$

While this is fundamental that the clinician establishes a standard reference shape and zone for the reference body when interpreting elevation maps, ${ }^{39}$ the concept of an enhanced elevation has been introduced by Belin and implemented on the Pentacam. ${ }^{19,20}$ After calculating the standard BFS for the $8 \mathrm{~mm}$ corneal zone, a second "enhanced" BFS for the same zone excluding the $3.5 \mathrm{~mm}$-diameter zone centered at the thinnest point is calculated. The difference map from the standard and enhanced BFS will exaggerate any differences (protrusions) within the excluded zone. More than $5 \mu \mathrm{m}$ of difference for the front elevation and $12 \mu \mathrm{m}$ difference for the back elevation are considered suspicious. ${ }^{19,20,22}$ Changes in posterior corneal elevation have been studied to document long-term stability after LASIK, so that using the same BFS for the preoperative corneal information, less than $7 \mu \mathrm{m}$ on the maximal difference in the central 4.0 $\mathrm{mm}$ zone was found on stable LASIK cases. ${ }^{40}$

Corneal thickness maps enable the characterization of the TP value and its location, along with thickness distribution. ${ }^{19,20,22}$ The TP is a more accurate parameter than central thickness for screening ectatic corneal diseases, ${ }^{19,20,22,27}$ as well as for calculating the percentage of 
tissue altered (PTA) and RSB. ${ }^{8,22}$ In the Pentacam, thickness distribution is described as the average of thickness values in concentric annular circles with increasing diameters centered on the TP. These values are presented in the corneal thickness spatial profile (CTSP) and the percentage of thickness increase (PTI) graphs, which also contain reference data (mean and 95\% confidence intervals) from a normal population..$^{19,20,22}$ In addition, a pachymetric progression index (PPI) is calculated for every one degree of meridians of the cornea, starting from the TP outward. This calculation considers the increase in thickness comparing to the TP at each point of the cornea, referencing to a normal population. The Ambrósio's relational thickness (ART) values are calculated as the ratios of the TP and the average of the PPI at all meridians (ARTAve) and the meridian with maximal PPI (ART-Max). ${ }^{20,22}$ The cut-off criteria for ART-Ave for clinical and mild FFKC were respectively 474 and $521 \mu \mathrm{m}$, with sensitivity and specificity of 99.59 and $98.19 \%$ for keratoconus and 91.49 and $93.05 \%$ for FFKC. For ART-Max, 386 and $416 \mu \mathrm{m}$ were the cut-offs which had respectively, sensitivity and specificity of 99.17 and $97.28 \%$ for keratoconus and 85.11 and $93.05 \%$ for subclinical disease. ${ }^{20}$

The Pentacam Belin/Ambrósio enhanced ectasia display (BAD) is a comprehensive display that combines the standard and enhanced BFS elevation maps of the front and back surfaces, and the thickness distribution data. Different tomographic parameters are presented as the standard deviation from normality toward disease (d values): Anterior and posterior elevation at the TP (8 mm BFS), change in anterior and posterior elevation of the standard and enhanced BFS, thinnest value and location, PPI, ART, and maximal curvature (KMax). The BAD-D final parameter is calculated based on a regression analysis to maximize accuracy for detecting ectatic disease. ${ }^{19,20,22,41}$ The BAD-D higher than 2.11 was a criteria with sensitivity and specificity of 99.59 and 100\% for diagnosing keratoconus, whereas for detecting mild or subclinical disease, the criteria of higher than 1.22 provided $93.62 \%$ sensitivity and $94.56 \%$ specificity. ${ }^{20}$ Interestingly, in a retrospective nonrandomized study involving preoperative LASIK data from an international pool comprising of 23 post-LASIK ectasia cases and from 266 stable-LASIK with over one year of follow-up, the criteria of BAD-D higher than 1.29 provided $87 \%$ of sensitivity and $92.1 \%$ of specificity. ${ }^{30}$ Even though, the BAD-D was the most accurate parameter in predicting ectasia risk, the data suggests room for further improvement.

\section{The Impact from Corneal Procedures}

While ectasia is much more common after LASIK, it has also been reported after surface ablation procedures. ${ }^{8,9}$
The excimer ablation itself has a biomechanical impact on the cornea, however, the LASIK flap has a more pronounced effect. ${ }^{10}$ Interestingly, there are reported cases of unilateral keratectasia after LASIK, whereas the fellow eye remained stable after photorefractive keratectomy $(\mathrm{PRK}){ }^{42}$

The relative contributions on corneal biomechanical properties of the lamellar delamination and side cuts at different depths were studied in vitro in organcultured human corneas using radial shearing speckle pattern interferometry. ${ }^{43}$ The loss of structural integrity, measured by a reducing corneal strain was much more pronounced due to the vertical cut through corneal lamellae and was proportionally dependent on the cut depth. The horizontal lamellar dissection had a mild nondepth dependent impact. ${ }^{43}$

\section{Finite Element Simulation}

The biomechanical effect of different LVC procedures can be simulated using finite element analysis. ${ }^{10}$ This approach may assist in the understanding of the surgical effect on the corneal structure. For that purpose, the impact from two extreme LASIK parameters but with the same PTAwere simulated on the same model eye with central curvature of 43.34D, and central thickness of $546 \mu \mathrm{m}$ using Optimeyes software (Integrated Scientific Services, Biel, Switzerland). Both LASIK procedures were designed with PTA of $39.4 \%$, femtosecond planar flap with $8 \mathrm{~mm}$ in diameter, and planned optical zone of $6.15 \mathrm{~mm}$. A thin flap of $90 \mu \mathrm{m}$ and ablation of $125 \mu \mathrm{m}$ to treat-8D (A125), and a thick flap with $150 \mu \mathrm{m}$ with $65 \mu \mathrm{m}$ (A65) ablation to treat-4D were compared to evaluate the percentage of induced stresses in the central stromal bed. The thick flap LASIK procedure leads to higher induced stresses than the thin flap LASIK case on this simulation. An overall stress increase of $6 \%$ was found in the A65 case, whereas 3\% of stress increase was observed in the A125 for a central $5 \mathrm{~mm}$ disk in the posterior half of the cornea (Fig. 8). Furthermore, ablation thickness profile had a direct impact on induced stresses in the stromal bed just below the ablation (A125: +31\%, A65: +22\%), whereas flap thickness rather influenced stress increase in stromal tissue below the flap periphery (A125: $+2 \%$, A65: $+20 \%$ ). Interestingly, different zonal stress increase was observed due to the differences on overall volume of tissue removal. ${ }^{44}$

Thereby, the complexity of the impact from LVC procedures on corneal structure requires individualized calculations considering different parameters from surgery and also from the patient preoperatively. Contemplation of the impact from the flap cut parameters may significantly improve clinical application of simplified models, such as the percentage of tissue altered (PTA) ${ }^{13}$ and the 


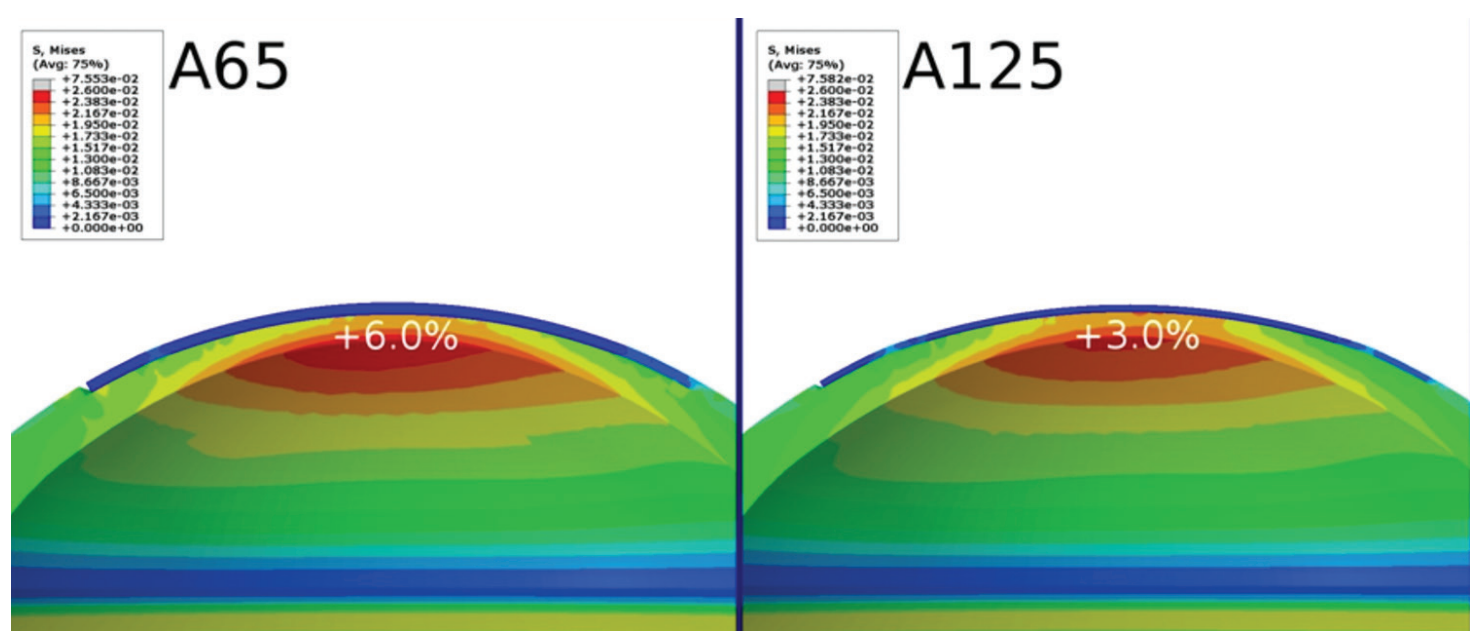

Fig. 8: Showing the distribution of equivalent stresses in the numerical surgery simulation models (thick-flap A65 on the left and for thin-flap A125 on the right). Stress values are given in megapascal (Mpa) and are color-coded (blue $=0.00 \mathrm{Mpa}$, red $=0.076 \mathrm{MPa}$ ). The two images show that the cut flaps do not carry any load and that the thicker flap (left) induced a higher average stresses than the thinner flap (right), with respect to the preoperative stress distribution. Simulations done by H. Studer, PhD (Optimo Medical AG; Bienne, Switzerland)

mathematical model to estimate the relative change in stromal tensile strength following PRK, LASIK, and small incision lenticule extraction. ${ }^{45}$

\section{Enhanced Screening for Ectasia Susceptibility}

"Everything should be as simple as possible, but not simpler." - Albert Einstein

An enhanced screening approach for the prevention of keratectasia should consider preoperative corneal data to estimate ectasia susceptibility and procedure related parameters. While this may be a challenging and complex task for the clinician to combine the data from different sources, artificial intelligence techniques, such as neural network (NN), decision tree (DT), support vector machine (SVM), and regression analysis have been used to facilitate clinical decisions. $8,18,24,27,30$

In a retrospective case control study, 177 normal eyes were compared to 148 eyes with clinical keratoconus and to 47 eyes with normal topography from 47 patients with clinical keratoconus in the fellow eye using the Galilei. A total of 55 parameters were analyzed so that a machine learning algorithm was created using a DT approach. Two machine learning algorithms were created using automated decision tree classifier. The one for the discrimination between normals and keratoconus had 100\% sensitivity and $99.5 \%$ specificity. The one developed for discriminating between normals and mild (subclinical) keratoconus had $93.6 \%$ sensitivity and $97.2 \%$ specificity. ${ }^{24}$ However, this is fundamental to validate such approaches in a new set of cases. In another study, a combination of corneal topography (I-S value) and minimum pachymetry from OCT was statistically the most significant in separating the ectatic from normal eyes. ${ }^{27}$
Recently, studies were accomplished to integrate shape and biomechanical analysis and develop the tomographic biomechanical index (TBI). The TBI combines data from the Corvis ST and the Pentacam HR (Oculus; Wetzlar, Germany), through a random forest method with leave-one-out cross-validation. This novel index has shown very high accuracy for detecting ectasia, including a very high sensitivity for subclinical ectasia among eyes with normal topography in very asymmetric patients, performing better than any other parameter tested ${ }^{46}$ For example, there are cases with normal topography and also normal tomography, including a BAD-D value lower than 1 but present with abnormal TBI. Figures 9 and 10 illustrate the clinical presentation of a patient with VAE in which the eye with normal topography has a very low BAD-D score and a TBI of 1 . Such analysis may provide a better understanding of ectasia susceptibility and also confirm if the fellow eye with normal front surface curvature is a mild or "fruste" keratoconus or if this is a factual unilateral ectasia patient.

The ectasia susceptibility score (ESS-I) was created based on the preoperative clinical and corneal tomography data from 23 cases that developed ectasia after LASIK and from 266 stable LASIK with over 1 year of follow-up. ${ }^{30}$ The regression formula combining BAD-D, age, and RSB was calculated. The cut-off of 0.068 ( $6.8 \%$ of relative risk) provided $100 \%$ sensitivity and $94 \%$ specificity, with better area under the receiver operating characteristic curve (AUC $=0.989 ; 95 \%$ CI: 0.969 to 0.998 ) than all parameters, including the BAD-D (AUC=0.931; CI: 0.895 to 0.957; De Long, $\mathrm{p}>0.001) .{ }^{30}$ Thereby, the ESS-I enables the calculation of the relative risk of developing ectasia accordingly to the BAD-D, age, and RSB. The logaritmic function leads 


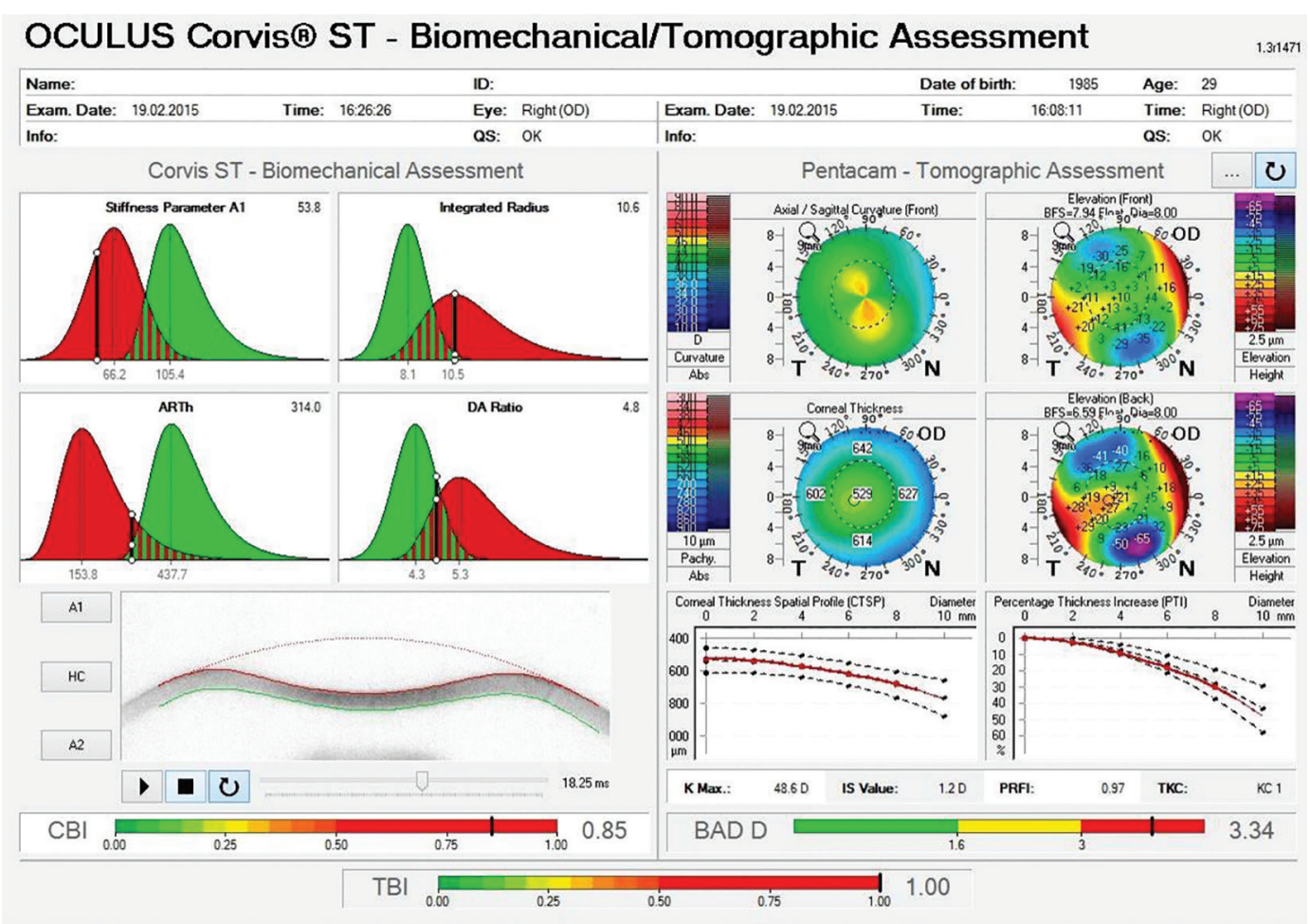

Fig. 9: Tomography and biomechanical assessment of the eye with mild ectatic presentation, from a VAE patient. The DCVA was 20/25+. Note the abnormal front surface curvature, with ID value of 1.2, BAD-D of 3.34 , and TBI of 1.0

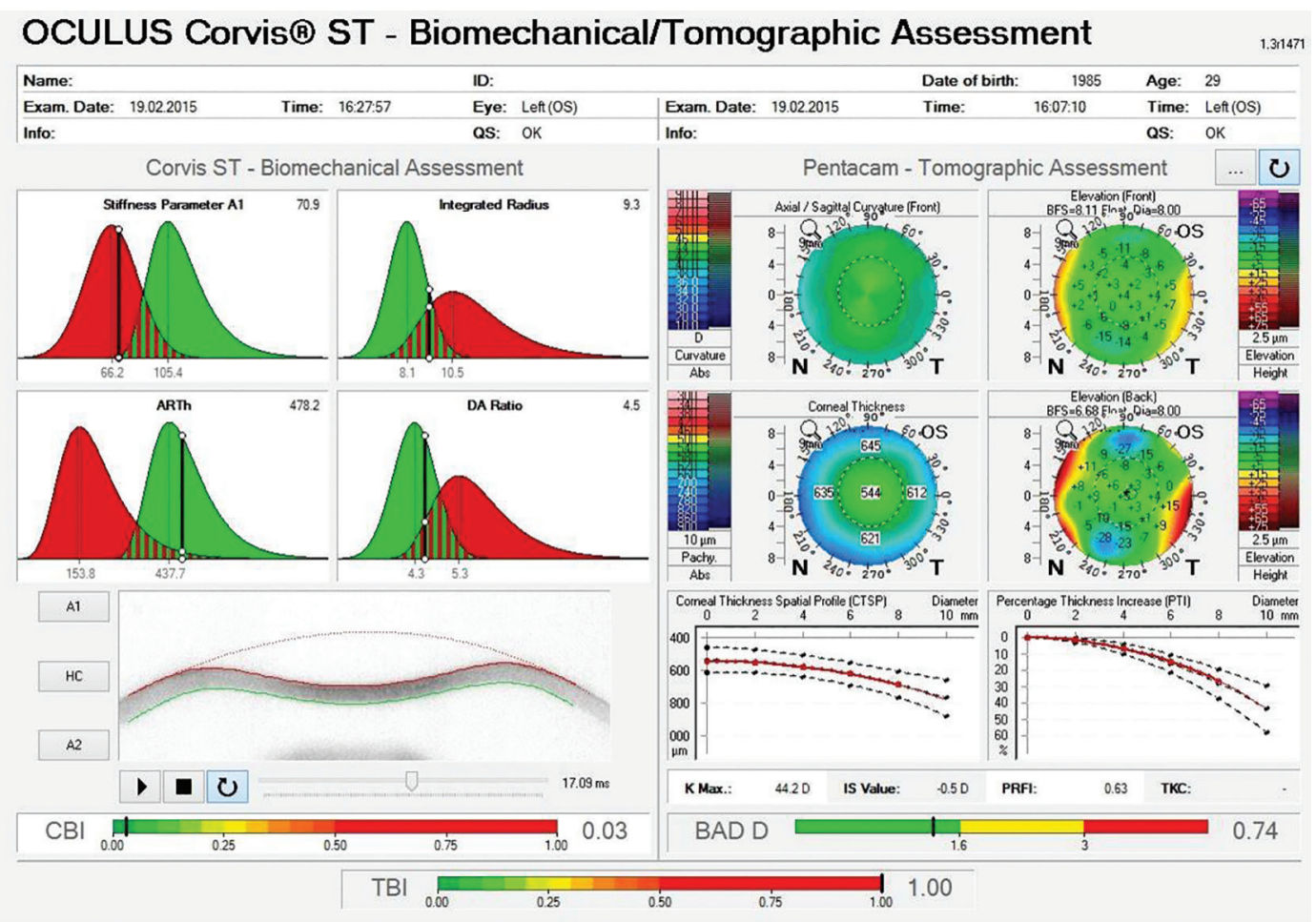

Fig. 10: Tomography and biomechanical assessment from the fellow eye of the same patient from Fig 9. The UDVA was 20/20. Note the BAD-D and I-S value lower than 1, but TBI of 1.0

to a binary outcome from zero to one, which represents the relative risk for ectasia. For example, a patient with 21 years old, BAD-D of 0.9 would be at high risk of ectasia (24\%) with $350 \mu \mathrm{m}$ of RSB. However, a patient with
21 years old, BAD-D of 0.2 and RSB of $350 \mu \mathrm{m}$ would be at low risk (3\%). Also, a patient with 42 years old, BAD-D of 0.9 would have low ectasia risk (1\%) with RSB of $350 .{ }^{30}$ Validation studies and further improvement for 
the conception of the enhanced ESS are currently being performed, including a larger set of 60 cases of ectasia with preoperative corneal tomography data (ESCRS 2014 Poster, Ramos et al). This is a work in progress by the Brazilian Study Group of Artificial Intelligence and Corneal Analysis (BrAIn), in which the refractive clinical data will be integrated to access the individualized risk of ectasia progression, accordingly to the procedure (Data integration: Key to Improve decision process in refractive surgery screening. Film produced by JM Lyra and R Ambrósio, 2016. https://www.youtube.com/ watch? $\mathrm{v}=\mathrm{z} 1 \mathrm{tUJkrUMDY}$ ).

\section{CONCLUSION AND FUTURE REMARKS}

Considering that there is high variability on subjective classifications of color coded maps, ${ }^{17}$ objective, and validated criteria is essential for diagnostic interpretation, and for the clinician to take full advantage of the diagnostic technologies. ${ }^{8,18,20,27}$ The analysis, using advanced corneal characterization of the preoperative state of cases that developed ectasia and of the ones that are stable after LVC represents the closest to ideal populations for the development and testing sensitivity and specificity of ectasia risk assessment approaches. Young age and low preoperative thickness are surrogates of corneal biomechanical properties, presenting as important risk factors for keratectasia. However, the advent of corneal biomechanical parameters may exclude these factors in artificial intelligence techniques, such as regression analysis, support vector machine, and random forest. Nevertheless, application of cross-validation techniques and external validations in separate populations are fundamental steps for the development of such methods, to ensure the clinical applicability and reliability for the test. Considering that keratectasia occurs due to a combination of preoperative predisposition or susceptibility of the patient's cornea and the impact from surgery on corneal structure, the approaches for assessing ectasia risk should consider a combination of patient-related data and procedure-related parameters. We anticipate fast developments and the integration of simulation analysis and artificial intelligence strategies, which will play a significant role in this field.

\section{REFERENCES}

1. Seiler T, Quurke AW. Iatrogenic keratectasia after LASIK in a case of forme fruste keratoconus. J Cataract Refract Surg 1998 Jul;24(7):1007-1009.

2. Pallikaris IG, Kymionis GD, Astyrakakis NI. Corneal ectasia induced by laser in situ keratomileusis. J Cataract Refract Surg 2001 Nov;27(11):1796-1802.

3. Spadea L, Cantera E, Cortes M, Conocchia NE, Stewart CW. Corneal ectasia after myopic laser in situ keratomileusis: a long-term study. Clin Ophthalmol 2012;6:1801-1813.
4. Rad AS, Jabbarvand M, Saifi N. Progressive keratectasia after laser in situ keratomileusis. J Refract Surg 2004 Sep-Oct;20 (Suppl 5):S718-722.

5. Moshirfar M, Smedley JG, Muthappan V, Jarsted A, Ostler EM. Rate of ectasia and incidence of irregular topography in patients with unidentified preoperative risk factors undergoing femtosecond laser-assisted LASIK. Clin Ophthalmol 2014;8:35-42.

6. Randleman JB, Russell B, Ward MA, Thompson KP, Stulting RD. Risk factors and prognosis for corneal ectasia after LASIK. Ophthalmology 2003 Feb;110(2):267-275.

7. Binder PS, Lindstrom RL, Stulting RD, Donnenfeld E, Wu H, McDonnell P, Rabinowitz Y. Keratoconus and corneal ectasia after LASIK. J Refract Surg 2005 Nov-Dec;21(6):749-752.

8. Ambrósio R Jr, Randleman JB. Screening for ectasia risk: what are we screening for and how should we screen for it? J Refract Surg 2013 Apr;29(4):230-232.

9. Dawson DG, Randleman JB, Grossniklaus HE, O'Brien TP, Dubovy SR, Schmack I, Stulting RD, Edelhauser HF. Corneal ectasia after excimer laser keratorefractive surgery: histopathology, ultrastructure, and pathophysiology. Ophthalmology 2008 Dec;115(12):2181-2191 . e1.

10. Dupps WJ Jr, Wilson SE. Biomechanics and wound healing in the cornea. Exp Eye Res 2006 Oct;83(4):709-720.

11. Padmanabhan P, Aiswaryah R, Abinaya Priya V. Post-LASIK keratectasia triggered by eye rubbing and treated with topography-guided ablation and collagen cross-linking-a case report. Cornea 2012 May;31(5):575-580.

12. Randleman JB, Trattler WB, Stulting RD. Validation of the ectasia risk score system for preoperative laser in situ keratomileusis screening. Am J Ophthalmol2008 May; 145(5):813-818.

13. Santhiago MR, Smadja D, Gomes BF, Mello GR, Monteiro ML, Wilson SE, Randleman JBAssociation between the percent tissue altered and post-laser in situ keratomileusis ectasia in eyes with normal preoperative topography. Am J Ophthalmol 2014 Jul;158(1):87-95 e1.

14. Ambrósio R Jr, Klyce SD, Wilson SE. Corneal topographic and pachymetric screening of keratorefractive patients. J Refract Surg 2003 Jan-Feb;19(1):24-29.

15. Duffey RJ,Hardten DR, Lindstrom RL, Probst LE, Schanzlin DJ, Tate GW, Wexler SA. Ectasia after refractive surgery. Ophthalmology2008 Oct;115(10):1849; autor reply 1849-1850.

16. Chan CC, Hodge C, Sutton G. External analysis of the Randleman ectasia risk factor score system: a review of 36 cases of post LASIK ectasia. Clin ExpOphthalmol 2010 May;38(4): 335-340.

17. Ramos IC, Correa R, Guerra FP, Trattler W, Belin MW, KlyceSD, Fontes BM, Schor P, Smolek MK, Dawson DG, et al. Variability of subjective classifications of corneal topography maps from LASIK candidates. J Refract Surg 2013 No;29(11):770-775.

18. Saad A, Gatinel D. Topographic and tomographic properties of forme fruste keratoconus corneas. Invest ophthalmol Vis Sci 2010 Nov;51(11):5546-5555.

19. Belin MW, Ambrósio R. Scheimpflug imaging for keratoconus and ectatic disease. Indian J Ophthalmol 2013 Aug;61(8): 401-406.

20. Ambrósio R Jr, Valbon BF, Faria-Correia F, Ramos I, Luz A. Scheimpflug imaging for laser refractive surgery. Curr Opin Ophthalmol 2013 Jul;24(4):310-320.

21. Ruiseñor Vázquez PR, Galletti JD, Minguez N, Delrivo M, Fuentes Bonthoux F, Pförtner T, Galletti JG. Pentacam 
scheimpflug tomography findings in topographically normal patients and subclinical keratoconus cases. Am J Ophthalmol 2014 Jul;158(1):32-40. e-2.

22. Ambrósio R Jr, Nogueira LP, Caldas DL, Fontes BM, Luz A, Cazal JO, Alves MR, Belin MW. Evaluation of corneal shape and biomechanics before LASIK. Int Ophthalmol Clin 2011 Spring;51(2):11-38.

23. Bae GH, Kim JR, Kim CH, Lim DH, Chung ES, Chung TY. Corneal topographic and tomographic analysis of fellow eyes in unilateral keratoconus patients using pentacam. Am J Ophthalmol 2014 Jan;157(1):103-109. e1.

24. Smadja D, Touboul D, Cohen A, Doveh E, Santhiago MR, Mello GR, Krueger RR, Colin J. Detection of subclinical keratoconus using an automated decision tree classification. Am J Ophthalmol 2013 Aug;156(2):237-246. e1.

25. Smadja D, Santhiago MR, Mello GR, Krueger RR, Colin J, Touboul D. Influence of the reference surface shape for discriminating between normal corneas, subclinical keratoconus, and keratoconus. J Refract Surg 2013 Apr;29(4):274-281.

26. Gomes JA, Tan D, Rapuano CJ, Belin MW, Ambrósio R Jr, Guell JL, Malecaze F, Nishida K, Sangwan VS; Group of Panelists for the Global Delphi Panel of Keratoconus and Ectatic Diseases. Global consensus on keratoconus and ectatic diseases. Cornea. 2015 Apr;34(4):359-369.

27. Rabinowitz YS, LiX, Canedo AL, Ambrósio RJr, Bykhovskaya Y. Optical coherence tomography combined with videokeratography to differentiate mild keratoconus subtypes. J Refract Surg 2014 Feb;30(2):80-87.

28. Ambrósio R Jr, Dawson DG, Salomão M, Guerra FP, Caiado AL, Belin MW. Corneal ectasia after LASIK despite low preoperative risk: tomographic and biomechanical findings in the unoperated, stable, fellow eye. J Refract Surg 2010 Nov;26(11): 906-911.

29. Bühren J, Schäffeler T, Kohnen T. Preoperative topographic characteristics of eyes that developed postoperative LASIK keratectasia. J Refract Surg 2013 Aug;29(8):540-549.

30. Ambrósio R Jr, Ramos I, Lopes B, Canedo1 ALC, Correa1 R, Guerra1 F, Luz A, Price Jr FW, Price MO, Schallhor S, Belin MW. Assessing ectasia susceptibility prior to LASIK: the role of age and residual stromal bed (RSB) in conjunction to Belin-Ambrósio deviation index (BAD-D). Rev Bras Oftalmol 2014 Mar-Apr;73(2):75-80.

31. McGhee CN, Kim BZ, Wilson PJ. Contemporary Treatment Paradigms in Keratoconus. Cornea 2015 Oct;34(Suppl 10): S16-S23.

32. Li Y, Tan O, Brass R, Weiss JL, Huang D. Corneal epithelial thickness mapping by Fourier-domain optical coherence tomography in normal and keratoconic eyes. Ophthalmology 2012 Dec;119(12):2425-2433.

33. Reinstein DZ, Archer TJ, Gobbe M. Stability of LASIK in topographically suspect keratoconus confirmed non-keratoconic by Artemis VHF digital ultrasound epithelial thickness mapping: 1-year follow-up. J Refract Surg 2009 Jul;25(7): 569-577.

34. Pahuja N, Shroff R, Pahanpate P, Francis M, Veeboy L, Shetty R, Nuijts RMMA, Roy AS. Application of high resolution OCT to evaluate irregularity of Bowman's layer in asymmetric keratoconus. J Biophotonics 2016 May;10(5):701-707.

35. Roberts CJ, Dupps WJ Jr. Biomechanics of corneal ectasia and biomechanical treatments. J Cataract Refract Surg 2014 Jun;40(6):991-998.

36. Scarcelli G, Pineda R, Yun SH. Brillouin optical microscopy for corneal biomechanics. Invest Ophthalmol Vis Sci 2012 Jan;53(1):185-190.

37. Vinciguerra R, Ambrósio R Jr, Elsheikh A, Roberts CJ, Lopes B, Morenghi E, Azzolini C, Vinciguerra P. Detection of Keratoconus with a new biomechanical index. J Refract Surg 2016 Dec;32(12):803-810.

38. Luz A, Lopes B, Hallahan KM, Valbon B, Ramos I, FariaCorreia F, Schor P, Dupps WJ Jr, Ambrósio R Jr. Enhanced combined tomography and biomechanics data for distinguishing forme fruste keratoconus. J Refract Surg. 2016 Jul;32(7):479-494.

39. Belin MW, Khachikian SS. An introduction to understanding elevation-based topography: how elevation data are displayed - a review. Clin Exp Ophthalmol 2009 Jan;37(1):14-29.

40. Ciolino JB, Khachikian SS, Cortese MJ, Belin MW. Long-term stability of the posterior cornea after laser in situ keratomileusis. J Cataract Refract Surg 2007 Aug;33(8):1366-1370.

41. Lopes BT, Ramos IC, Dawson DG, Belin MW, Ambrósio R Jr. Detection of ectatic corneal diseases based on pentacam. Z Med Phys 2016 Jun;26(2):136-142.

42. Kymionis GD, Tsiklis N, Karp CL, Kalyvianaki M, Pallikaris AI. Unilateral corneal ectasia after laser in situ keratomileusis in a patient with uncomplicated photorefractive keratectomy in the fellow eye. J Cataract Refract Surg 2007 May;33(5): 859-861.

43. Knox Cartwright NE, Tyrer JR, Jaycock PD, Marshall J. Effects of variation in depth and side cut angulations in LASIK and thin-flap LASIK using a femtosecond laser: a biomechanical study. J Refract Surg 2012 Jun;28(6):419-425.

44. Studer HP, Riedwyl H, Amstutz CA, Hanson JV, Büchler P. Patient-specific finite-element simulation of the human cornea: a clinical validation study on cataract surgery. J Biomech 2013 Feb ;46(4):751-758.

45. Reinstein DZ, Archer TJ, Randleman JB. Mathematical model to compare the relative tensile strength of the cornea after PRK, LASIK, and small incision lenticule extraction. J Refract Surg 2013 Jul;29(7):454-460.

46. Ambrósio R Jr, Lopes B, Faria-Correia F, Salomao M, Buhren J, Robets C, Elsheikh A, Vinciguerra R, Vinciguerra P. Integration of Scheimpflug based Corneal Tomography and Biomechanical Assessments for Enhancing Ectasia Detection. J Refract Surg 2017. 